\title{
Echocardiographic sign of right-sided hypertrophic obstructive cardiomyopathy
}

\author{
E. ASIN CARDIEL, M. ALONSO, J. L. DELCAN, AND L. MENARGUEZ \\ From Ciudad Sanitaria Provincial 'F.F.', Servicio de Cardiologia y Cirugia Cardiovascular, \\ Madrid, Spain
}

SUMMARY The echocardiographic and haemodynamic findings in a patient with hypertrophic obstructive cardiomyopathy (HOCM) and dynamic subpulmonary stenosis, without left ventricular gradient, are described. The echocardiogram shows not only asymmetric septal hypertrophy, systolic anterior movement of the anterior mitral leaflet, and midsystolic collapse of the aortic valve, but also increase in the right ventricular wall echoes and systolic collapse of the pulmonary valve.

We believe that in the absence of pulmonary hypertension these signs, particularly the systolic closing movement of the pulmonary valve cusp, may suggest right ventricular obstruction in HOCM.

The M-mode echocardiographic features of hypertrophic cardiomyopathy with (Shah et al., 1969; Henry et al., 1973b) and without (Henry et al., 1973a) left ventricular outflow tract obstruction are well established. The case reported here suggests that associated right ventricular obstruction (Lockhart et al., 1966; Befeler et al., 1973) can be identified by single dimension echocardiography.

\section{Case report}

A 15-year-old boy presented with effort dyspnoea. The peripheral pulses were slightly jerky, the blood pressure was $120 / 80 \mathrm{mmHg}$, and the jugular venous pressure was normal, with a dominant $a$ wave. A sustained right ventricular impulse was palpable and there was a grade $3 / 4$ ejection systolic murmur which became louder on inspiration and quieter with the Valsalva manoeuvre.

The electrocardiogram showed probable biatrial hypertrophy and severe right ventricular hypertrophy with $3 \mathrm{~mm}$ ST segment depression in right praecordial leads. The plain chest $x$-ray film showed mild pulmonary venous dilatation but normal heart size.

At right and left heart catheterisation, the pulmonary artery pressure was $20 / 11$ (mean 15) $\mathrm{mmHg}$; simultaneous recording in the right ventricular inflow and outflow tracts showed a $20 \mathrm{mmHg}$ systolic gradient. No gradient was recorded in the left ventricular cavity at rest, during catecholamine administration, or after ectopic beats. Right and left ventriculography (Fig. 1a, b) showed protrusion of the interventricular septum into both ventricular outflow tracts; this was more conspicuous on the right side. Left ventricular outflow tract obstruction was not seen, but infundibular obstruction resulting from hypertrophy of the crista supraventricularis and thickening of the septum was clearly defined. The pulmonary valve cusps were normal.

Right heart echocardiography (Fig. 2) demonstrated systolic flutter with striking mid-systolic collapse of the pulmonary valve, abnormally strong septal echoes behind the pulmonary valve, and thickening of the right ventricular anterior wall. Echocardiograms from the left heart (Fig. 3a and b) showed a thick interventricular septum (septal/left ventricular posterior wall ratio $>1 \cdot 5 / 1$ ), a small left ventricular cavity, diastolic contact between the mitral anterior leaflet and the septum, anterior systolic motion of the mitral apparatus, and systolic collapse of the aortic cusps.

\section{Discussion}

Hypertrophic cardiomyopathy is classically associated with predominant left-sided obstruction, but isolated (Morrow et al., 1969) and dominant (Befeler et al., 1973) right ventricular outflow tract obstruction have been described. Though in the present case no left ventricular gradient was recorded, the left heart echocardiographic findings, particularly systolic collapse of the aortic cusps (Fig. 3b), suggest that left ventricular obstruction 


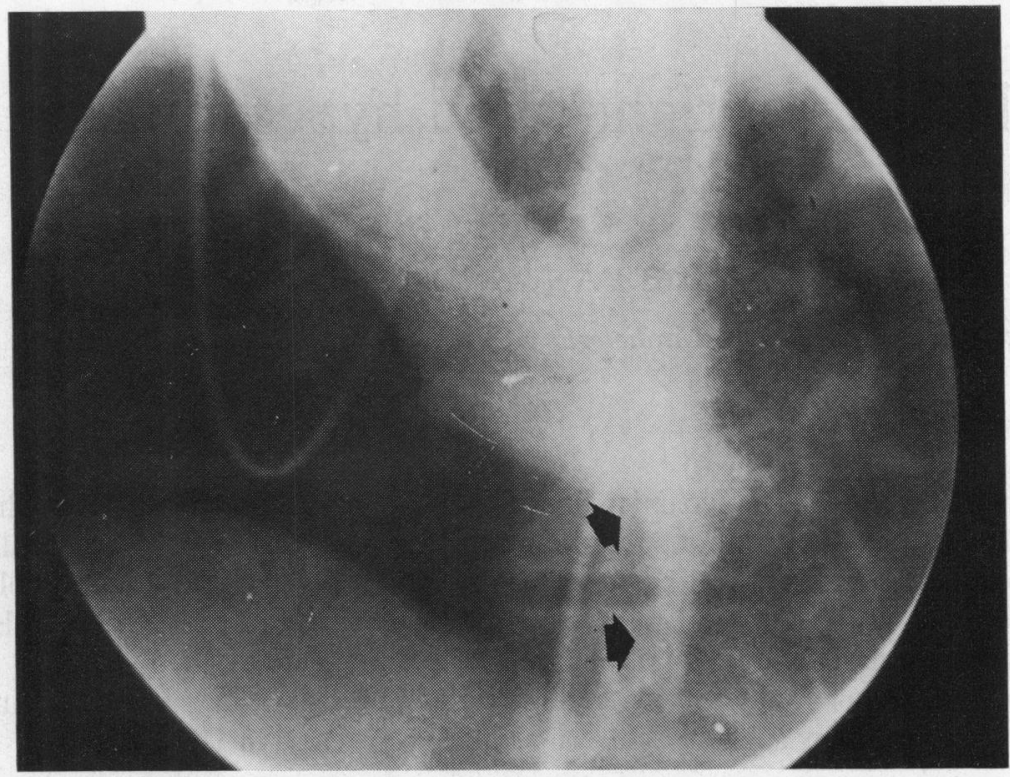

Fig. 1a

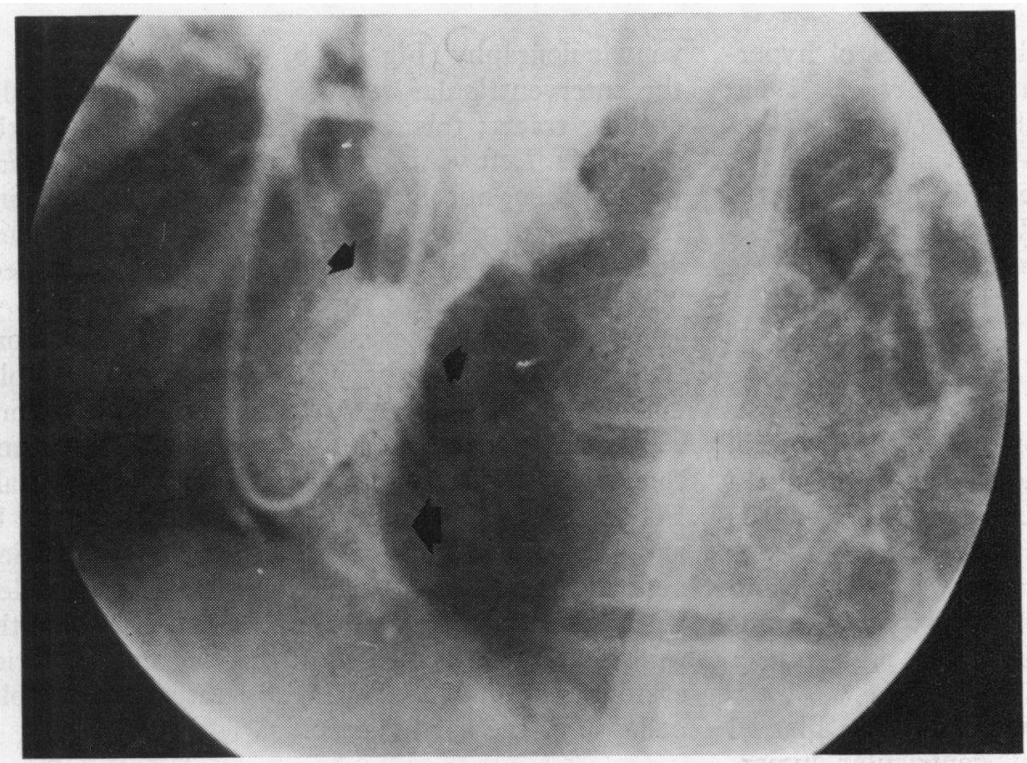

Fig. 1 (a) Left ventriculogram in systole (left anterior oblique). The asymmetric septal hypertrophy is seen (arrows), with wide outflow tract. (b) Right ventriculogram in systole (left anterior oblique). The predominantly right-sided septal protrusion is observed (lower arrows), as well as cristal hypertrophy causing infundibular stenosis (top arrow).

was present at the time of the ultrasonic examination. It thus seems reasonable to conclude that this patient had hypertrophic cardiomyopathy with dominant left ventricular outflow tract obstruction.

Systolic collapse of the pulmonary valve has been shown echocardiographically in pulmonary hypertension (Weyman et al., 1974) and isolated infundibular stenosis (Nanda et al., 1975) but has not previously been reported in hypertrophic cardiomyopathy. In this case it occurred with, and pre- sumably reflected, conspicuous infundibular obstruction. Whether this echocardiographic finding can reliably identify the right-sided obstruction commonly associated with predominantly left-sided obstructive cardiomyopathy (Swan et al., 1971) is a matter for further investigation. The observations reported here do, however, suggest that examination of the pulmonary valve might usefully be included in the echocardiographic assessment of all patients with hypertrophic cardiomyopathy. 


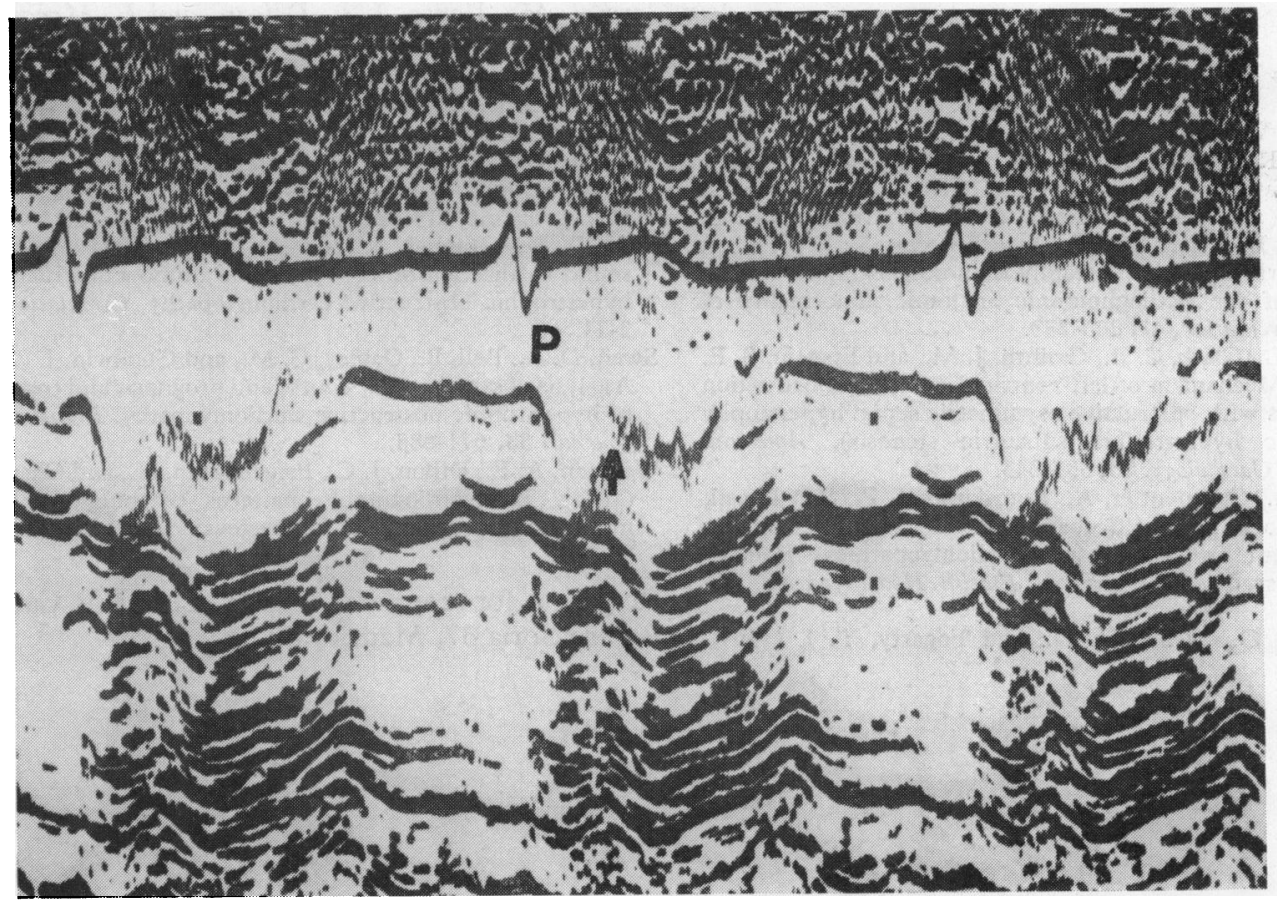

Fig. 2 Echocardiogram showing pulmonary valve. Thick echoes behind the pulmonary valve produced by infundibulum. Pulmonary cusp $(P)$ with fluttering in systole (arrow) and distinct midsystolic collapse, caused by dynamic subpulmonary stenosis.

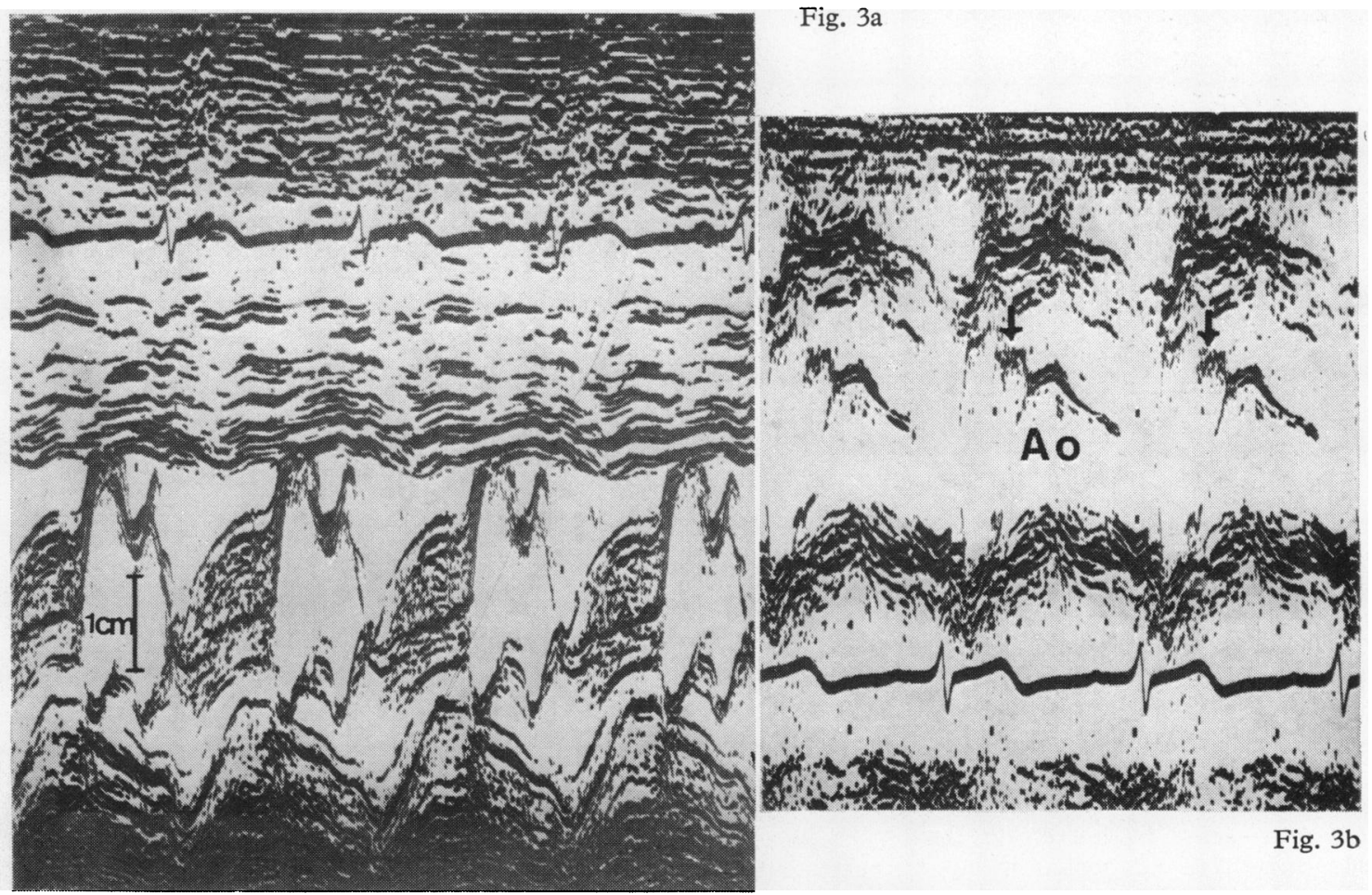

Fig 3. (a) Echocardiogram showing the ventricular cavities and the mitral valve. There is right ventricular enlargement, with increased thickness of the echoes from the anterior wall, and asymmetric septal hypertrophy. The mitral valve shows an anterior systolic movement. (b) Echocardiogram showing aortic root with normal opening of the aortic valve cusps in systole and midsystolic collapse (arrows). 


\section{References}

Befeler, B., Wells, D. E., Machado, H., Castellanos, A., Jr. Lazzara, R., and Myerberg, R. J. (1973). Haemodynamic characteristics of obstructive cardiomyopathy of the right ventricle (abstract). Circulation, 47 and 48, Suppl. IV, 143.

Henry, W. L., Clark, C. E., and Epstein, S. E. (1973a). Asymmetric septal hypertrophy. Echocardiographic identification of the pathognomonic anatomic abnormality of IHSS. Circulation, 47, 225-233.

Henry, W. L., Clark, C. E., Griffith, J. M., and Epstein, S. E. (1973b). Mechanism of left ventricular outflow obstruction in patients with obstructive asymmetric septal hypertrophy (idiopathic hypertrophic subaortic stenosis). American fournal of Cardiology, 35, 337-345.

Lockhart, A., Charpentier, A., Bourdarias, J. P., Ben Ismail, M., Ourback, P., and Scebat, L. (1966). Right ventricular involvement in obstructive cardiomyopathies. Haemodynamic studies in 13 cases. British Heart fournal, 28, 122-133.

Morrow, A. G., Fisher, R. D., and Fogarty, T. J. (1969).
Isolated hypertrophic obstruction to right ventricular outflow. American Heart fournal, 77, 814-817.

Nanda, N. C., Gramiak, R., Manning, J. A., and Lipchik, E. O. (1975). Echocardiographic features of subpulmonic obstruction in dextro-transposition of the great vessels. Circulation, 51, 515-521.

Shah, P. M., Gramiak, R., and Kramer, D. H. (1969). Ultrasound localization of left ventricular outflow obstruction in hypertrophic obstructive cardiomyopathy. Circulation, 40, 3-11.

Swan, D. A., Bell, B., Oakley, C. M., and Goodwin, J. (1971). Analysis of symptomatic course and prognosis and treatment of hypertrophic obstructive cardiomyopathy. British Heart Fournal, 33, 671-685.

Weyman, A. E., Dillon, J. C., Feigenbaum, H., and Chang, S. (1974). Echocardiographic patterns of pulmonic valve motion with pulmonary hypertension. Circulation, 50, 905-910.

Requests for reprints to Dr E. Asin Cardiel, Arturo Soria 37, Madrid, Spain. 